\title{
The Influence of Technology on English Language and Literature
}

\author{
Laila Al-Sharqi ${ }^{1} \&$ Irum Saeed Abbasi ${ }^{2}$ \\ ${ }^{1}$ King AbdulAziz University, Jeddah, Saudi-Arabia \\ ${ }^{2}$ San Jose state University, CA, USA \\ Correspondence: Irum Saeed Abbasi, San Jose state University, CA, USA
}

Received: April 18, 2020

Accepted: June 2, 2020

Online Published: June 9, 2020

doi: $10.5539 /$ elt.v13n7p1

URL: https://doi.org/10.5539/elt.v13n7p1

\begin{abstract}
In the current global scenario, the Internet is increasingly becoming a central informational medium that is transforming the way we learn, teach, and communicate. Social media offers a public platform that allows an exchange of thoughts and ideas through posts, tweets, and comments, albeit with word or character count restrictions. Evidently, creativity cannot be curtailed through content length restrictions. The emergence of a new genre of short-stories called short-short stories and the birth of a new English dialect called Text-speak prove that every cloud indeed has a silver lining. The popularity of social media exchanges signify that technology users have accepted quick social media interactions as a new way of life and have also adjusted their writing to match the content restrictions. Educators and parents are concerned that the attitudes and habits of tech-savvy generation are muddying Standard English as Text-speak is infiltrating students assignments blurring the distinction between formal and informal writing. The phenomenal popularity of short stories that can fit in a tweet or text is an example of how adversity can be turned into an opportunity. Literary purists, however, are concerned that digital literature is shrinking and short-stories are severing their characteristic elements to comply with the restrictions. This paper delineates the impact of technology on daily English writing and literature.
\end{abstract}

Keywords: flash fiction, internet slang, online communication, net-generation, social media, short-hand writing, short-short stories, text-speak, twitter fiction

\section{Introduction}

Would Shakespeare be able to read and comprehend the truncated English content currently circulated on the Internet? Being the greatest English writer for generations to come, is this even a fair question to ask? May be yes. The English he knew and promoted is eroding at a fast pace due to the restricted length of online content. These restrictions and the ubiquity of quick social interactions have fueled a new era of English language and literature adjustments. Consequently, a new short hand English dialect called Text-speak and a new genre of short story called flash fiction have surfaced. Text-speak is especially popular among the digital natives or net-generation (Rosen et al., 2010). The net-generation adeptly uses online resources to develop thinking skills, experiment with different methods of learning, gain self-understanding, complete school work, and collaborate with peers and teachers. Nevertheless, the constant information influx in the form of tweets, emails, posts, and comments can be mentally exhaustive. Unsurprisingly, with this information deluge, students have less time to perfect their assignments. As a result, Text-speak frequently appears in students assignments and adversely affect their school performance. Therefore, teachers are sounding alarms about the disadvantages of Text-speak and emphasize that Standard English is the bed rock of academic and professional success in English speaking countries. This paper examines how technology has influenced English language and literature.

\section{The Influence of Technology on Learning}

Internet users can potentially use the unlimited online resources for learning, communication, career planning, and developing relationships. Technology provides students with essential learning tools that facilitate cooperative learning, offer exciting alternatives for developing language skills through experimentation (Ahmadi, 2018), and aid students in learning the operating rules of formal and informal languages (Douglas, 2009). Internet based learning promotes students autonomy and increases their motivation making the learning experience more student-centered (Ahmadi, 2018). Many schools now encourage students to use online resources to enhance learning and provide online portals that enable students to submit their assignments, check grades, and collaborate with peers (Strain-Moritz, 2016). 


\section{Technology Distractions}

Although a recent literature review concluded that technology promotes students creativity and improves language learning skills (Ahmadi, 2018), The Internet facilitates short and frequent communications through restricted tweets and posts. It is also plausible that the incessant flow of digital information has rendered Internet users (users, hereafter) to be attention deficient. The Internet then capitalizes on the short attention spans and provide social media platforms that evoke technology addiction.

Born in the age of technology, the net-generation is particularly proficient in engaging with virtual peers through quick social media exchanges to develop a sense of belonging and combat the fear of missing out on popular activities. For example, the net-generation adeptly multi-tasks digital activities (Bromley, 2010) such as checking social media, browsing websites, reading emails, sending instant messaging, listening to music, and viewing ads, all while also managing their school work. This constant incoming information is not conducive to learning and staying focused on the school task. In a research study, students admitted to multi-tasking their school work with other online activities and reported that online activities distracted them from concentrating on academic tasks, which sometimes resulted in incomplete assignments (Adams, 2007). Therefore, the lure to engage in online activities leaves students struggling and hinders their academic success. Furthermore, students report feeling less inspired to use Standard English (Strain-Moritz, 2016), which could explain their low commitment to perfection and grammar.

\section{Social Media and Text-Speak}

Social communication, generally, enables us to put our thoughts into words, use words to develop bonds, deliver important information, learn from our experiences, and continue to build on work done by others (Shariatmadari, 2019). Social media has revolutionized social interactions and offers an unrestricted access to people across the globe. Social media clicks allow quick interactions through popular features such as tags, likes, retweets, and reposts. This ease of sharing makes digital social communications infinite. Social media has also created the need for a short-term dialect (Akbarov \& Tankosić, 2016), which is interchangeably called Textese, Digi-talk, Text-speak, Tech-speak, and Internet slang (Akbarov \& Tankosić, 2016; Cingel \& Sundar, 2012; Drouin \& Davis, 2009). In both, private and public online interactions, Text speak is the main mode of public and private communication of the net-generation (Moyle, 2010). To the fury of teachers and parents, Text-speak reads like a short spurt of truncated content rife with incomplete sentences, mis-spelled words, and emojis (symbols that mostly convey a feeling).

Text speak is rooted in Standard language, but it emulates the colloquial spoken language (French, 2018). Acronyms and simplistic spellings are used in Text-speak to facilitate efficient typing on mobile devices. Essentially, to partake in brief interactions and show their online presence, the net generation has modified standard English words (i.e., word adaptation) using abbreviations (e.g., brb for be right back), omitted non-essential alphabets (i.e., wud for would), substituted homo-phones (gr8 for great), and de-emphasized appropriate punctuation and capitalization causing structural adaptations to the English language (Cingel, \& Sundar, 2012). For more examples of Text-speak words, please see Table 1. Text-speak could also be deemed as an effort by teens to codify (youth code; French, 2018) communications to protect them from unintended recipients (parents; Akbarov \& Tankosić, 2016). Moreover, Text-speak could also be considered a manifestation of rebellion against language rules (Akbarov \& Tankosić, 2016).

The word adaptations seen in Text-speak spill into daily English language use. Not surprisingly, routinely using textual adaptations may give off an impression of normalcy and acceptance, which makes it difficult to learn standard English (Cingel \& Sundar, 2012). Standard English refers to the correct use of vocabulary and grammar in communications (Baker, 2014). It is also the form of language that is accepted in government offices, academia, and in other formal contexts (Birner, 1991). Text-speak tramples upon Standard English rules and presents a challenge to academicians and parents. Educators are concerned that abbreviated content rampant with misspelled words and grammatically incorrect sentences are creeping into students assignments, which blurs the distinction between formal and informal writing (Strain-Moritz, 2016). Results from a study showed that there is an inverse relationship between texting and professionally written communication and reading accuracy in a sample of college students (Drouin, 2011). In this day and age, grammar and language are both collapsing (Sonn, 2006); users are increasingly turning away from reading and writing in Standard English. Basically, conventional writing, that once required the proper use of Standard grammatical rules, has apparently fallen into an abyss. Table 1. lists some of the example of Text-speak words. 
Table 1.

\begin{tabular}{cc}
\hline Standard English & Text-speak \\
\hline me & meh \\
cause & cuz \\
fight me & fite me \\
Oh my God & omg \\
Never mind & nvm \\
Forgive & 4give \\
about & aboot \\
the & da \\
people & ppl \\
your & ur
\end{tabular}

Students and parents are aware of the drawbacks of Text-speak. There is a plethora of research that points to the disadvantages of using Text-speak. For example, students who engaged in informal online communications also reported avoiding a higher level of vocabulary (Adams, 2007), and more than half of the students in another study reported that frequent texting was responsible for their difficulty in recalling Standard English (Drouin \& Davis, 2009). These findings were further validated by another study. Researchers found that in academic writing, $64 \%$ of students engaged in informal writing, 50\% reported using incorrect mechanics (grammar, punctuation), 38\% reported using text shortcuts, and 25\% reported using emoticons (Lenhart et al., 2008). Based on these statistics, it is not surprising that students are increasingly becoming oblivious to using correctly spelled words or using proper grammar and/or punctuation.

Teachers, parents, and students agree, alike, that effective writing is an important factor in achieving academic and professional success. For example, employees or students who are skilled in using grammar correctly are entrusted with representing their company or school in written communications (Rushkoff, 2013) and are more valuable and promotable than those whose ambiguous writing style create uncertainty, confusion, legal liability, and embarrassment (Rushkoff, 2013). Research studies have also underscored the importance of effective writing to succeed in later life. For instance, in multiple studies, researchers asked teachers, students, and parents about the importance of effective writing in life. The results revealed that $92 \%$ of 2,462 teachers contended that writing effectively is required to succeed in life (Purcell et al., 2013). Similarly, $86 \%$ of students opined that good writing is important to succeed in life, and $83 \%$ of parents believed that students ought to write well to be successful in life (Lenhart et al., 2008). The parents also showed concern and reported that there is an increasing need for effective writing in this age than there was twenty years ago (Lenhart et al., 2008).

Notwithstanding the efforts to teach Standard English language rules at schools, children fail to apply those rules outside the classroom or even in examinations. For example, researchers investigated if there had been a change in the level of formality in sixteen-year old students writing between 2004 and 2016 by examining 858 extracts that were given as a part of English Language examination (Constantinou et al., 2019). The results showed that students writing between both years became more informal, and that the informal writing trend was stronger among low achieving students. It is noteworthy that, currently, children are writing more than they did twenty years ago. Nevertheless, it seems that their ability to correctly remember Standard English language rules is hindered (Merritt, 2013). However, research has also shown that primary school children who made fewer punctuation errors during texting were more likely to exhibit a better grasp of Standard English spellings and were more capable of processing English writing quickly (Smith, 2015).

All arguments aside, we can all agree that technology is here to stay and Text-speak is the main mode of communication used by the net-generation. Parents and teachers must make a difficult choice: either accept and recognize Text-speak as a skillful dialect or reject it as an unorthodox alien language. It is important to acknowledge that humans are wired to acquire the language and dialect articulated around them. Therefore, the net-generation cannot be blamed for developing the capacity to process, analyze, and evaluate Text-speak messages and adeptly produce a reply to share opinions, ideas, personal experiences, and narratives (Moyle, 2010). If Standard English is considered a dialect of English; the new language promoted by the techno-savvy generation could be deemed as a newer dialect of the English language. Interestingly, researchers found that there is a positive relationship between frequent text messaging, reading fluency, and spelling accuracy (Drouin, 2011). Another 
study indicated that frequency of Text-speak did not have a correlation with poor grammar in text messages or children grasp of written or spoken grammar (Merritt, 2013). These students were able to develop arguments, write thesis statements, and structure their thoughts appropriately, which may serve as a reassurance to parents who fear that Text speak may be degrading their_children's grasp of Standard English (Merritt, 2013).

The tide is changing; some socio-linguists have recognized the importance of accepting Text-speak as a new genre (French, 2018). Standard English dictionaries have also started including certain words and phrases of Text-speak into their online versions. Therefore, educators should recognize Text-speak as a new subset, genre, or branch of the cultural and social language (Douglas, 2009), and acknowledge it rather than derogating it as a lousy language. Birner (1991) argues that no dialect can be called 'sloppy' or 'lazy' as each dialect of every language is governed by some rules, albeit not schoolroom rules. Those rules inform us what language is like instead of what language should be like (Birner, 1991). Some argue that critical literacy should explore all modes of communication, irrespective of whether we consider them valuable or not, owing to the fact the any communication signifies participation in society (Kaplan, 1995).

Table 2 shows the words and phrases included in the Oxford online dictionary from Text-speak

Table 2.

\begin{tabular}{cc}
\hline Standard English & Text-speak \\
bring your own device & BYOD \\
seriously & srsly \\
dance to popular music & twerk \\
too long didnt read & TL;DR \\
great delight & squee \\
photograph taken by oneself & selfie \\
long distance relationship & LDR \\
congratulations & grats \\
time spent relaxing & me time \\
laugh out loud & LOL \\
\hline
\end{tabular}

In the UK, children as young as eight are considered bilingual if they are proficient in Standard English and Text-speak (Merritt, 2013). Giving recognition to text speak as a dialect of the English language can help students achieve a better understanding of the appropriate time to use Text-speak. After all, online content challenges our mental capacities to reprogram our receptive powers and thinking processes in order to adapt to the digital world (Bromley, 2010). Additionally, English vocabulary is growing at a fast pace due to the incessant additions of new technology promoted words many of which cultivate clarity, creativity, and ease of expression (Purcell, Buchanan, $\&$ Friedrich, 2013). For example, with the popularity of the google search engine, the phrase google it carries the same meaning as search it. Therefore, encouraging students to use new vocabulary in Text-speak could benefit students and parents.

We can all agree that technology is here to stay and Text-speak is the main mode of communication used by the net-generation. Parents and teachers have to make a difficult choice: either accept and recognize Text-speak as a skillful dialect or reject it as an unorthodox alien language. In this case, teachers and parents must recognize text speak as a skillful dialect that requires complex skills to analyze and decipher the language. In order to comprehend the written communications of the net-generation, educators, and parents are forced to enter the unchartered territory of Text-speak to acclimatize linguistically. Fortunately, there are Text-speak translators and manuals that help parents decipher online messages (Akbarov \& Tankosić, 2016).

Considering the changing trends, accepting Text-speak as a skillful language seems to be the only appropriate choice.

\section{Technology and Literature}

Technology is advancing at a high pace and literature is changing with it. With the advent of social media, quick digital interactions appear to be the future of social communication. Because readers emotional, temporal, and spatial relationship with books is changing rapidly (Sesek \& Pusnik, 2014), the production and consumption of literature is also evolving to shorter and more frequent communications (Strain-Moritz, 2016). Short-short digital stories are now considered a new literary genre with different aliases such as flash fiction, mini-fiction, minute 
stories, sudden fiction, hint fiction, mobile phone fiction, and twitter fiction (Barnard, 2016). As the names suggests, these stories are extremely brief mostly due to the character or word count restrictions. For example, twitter imposes a 280 characters limit for each tweet, which increased from 140 characters (For a review see Al Sharqi \& Abbasi, 2015, 2016). It is not surprising that short-short digital stories lack the traditional elements of a story including setting, characters, plot, conflict, and resolution. Short-short digital stories also lack vivid description and articulate expressions of characters; therefore, readers connect with characters using their own experiences or the experiences of others (Sethi, 2017). In addition, authors are also forced to filter out unnecessary information, digressions, extraneous descriptions, and iterations while also compensating for the lack of details with acronyms, contractions, puns, alliterations, rhythms, and even typos. Advocates of short-short stories claim that social media promotes a sophisticated form of literary performance art (Franklin, 2014).

The trend of sharing thoughts in miniature form is growing in demand partly because of the diminishing attention spans of the readers. The authors aim to attract whatever amount of attention they can garner from readers with mite-sized attention span (Rudin, 2011). Opponents of short-short stories call post-modern digital stories as plot less anti-stories (Patea, 2012) and compare it with a lightweight accessory written for lightweight thinkers (Penny, 2014). Literary purists argue that brevity comes at the cost of quality and decry a perceived decline in language proficiency. Others argue that social media communications may have contributed to "the linguistic ruin of generation" (Axtman 2002). It is noteworthy that writing extremely short stories is not a new phenomenon. Renowned authors had previously written both prose and poetry in extreme brevity. For instance, Ernest Hemingway wrote his legendary six words story: "For Sale: baby shoes, never worn". Nevertheless, the popularity of sharing short-short stories has increased manifolds with digital story telling. In essence, technology has phenomenally affected both language and literature. Inevitably, language and literature will continue to evolve with further technology advancements and new dialects and literary genres will appear. It is up to us to ensure that Standard English is not tainted or forgotten with the changing trends.

\section{Conclusion}

Internet has connected the world irrespective of time and space. Technology has influenced how we write, think, and communicate with others. The popularity of quick social interactions on social media has transformed our communication patterns and gave birth to Text-speak, which is the main mode of communication of the net-generation. The youngsters cannot to be blamed for writing in short-hand as they have adapted their writing style to comply with the word count restrictions. Text speak is now considered a dialect of English language and children are considered bilingual if they can communicate in Standard English and text-speak. The concern with short hand writing surfaces when Text-speak infiltrates academic writing and affects students' performance. At the same time, social media has also contributed to the popularity of twitter/flash fiction. The length of these stories matches the attention spans of the technology savvy readers. With further technological advancements, we can be sure to see more dialects and genres formed as a product of necessity

\section{References}

Adams, J. (2007). Student perceptions of the impact of instant messaging on academic writing. Literacy Learning: The Middle Years, 37. https://www.questia.com/library/journal/1G1-166201100/student-perceptions-of-the-impact-of-instant-mess aging

Ahmadi, M. R. (2018). The use of technology in English language learning: A literature review. International Journal of Research in English Education, 3(2), 115-125. https://doi.org/10.29252/ijree.3.2.115

Akbarov, A. \& Tankosić, A. (2016). Impact of Social Networks and Technology on English Language Learners. Journal of Linguistic Intercultural Education, 9(3), 7-28. https://doi.org/10.29302/jolie.2016.9.3.1

Al Sharqi, L. \& Abbasi, I. S. (2015). Flash fiction: A unique writer-reader partnership. Studies in Literature and Language, 11(1), 52-56.

Al Sharqi, L. \& Abbasi, I. S. (2016). Twitter Fiction: A New Creative Literary Landscape. Advances in Language and Literary Studies, 7(4), 16-19. https://doi.org/10.7575/aiac.alls.v.7n.4p.16

Axtman, K. (December 2002). $r$ u online?: The evolving lexicon of wired teens. Christian Science Monitor. Retrieved from https://www.csmonitor.com/.

Baker, F. (2014). Is Social Media Killing Literature? Retrieved from https://www.thelondonmagazine.org/is-social-media-killing-literature-by-francesca-baker/ 
Barnard, J. (2016). Tweets as microfiction: on Twitters live nature and 140-character limit as tools for developing storytelling skills. New Writing: The International Journal for the Practice \& Theory of Creative Writing, 13(1), 3-16. https://doi.org/10.1080/14790726.2015.1127975

Bromley, K. (2010). Picture a world without pens, pencils, and paper: The unanticipated future of reading and writing. Journal of College Reading \& Learning, 41(1), 97-108. https://doi.org/10.1080/10790195.2010.10850337

Bull, S. \& Ma, Y. (2001) Raising learner awareness of language learning strategies in situations of limited recourses. Interactive Learning Environments, 9(2), 171-200. https://doi.org/10.1076/ilee.9.2.171.7439

Cingel, D. P. \& Sundar, S. S. (2012). Texting, techspeak, and tweens: The relationship between text messaging and English grammar skills. New Media \& Society, 14(8), 1304-1320. https://doi.org/10.1177/1461444812442927

Constantinou, F., Chambers, L., Zanini, N. \& Klir, N. (2019). A diachronic perspective on formality in students writing: Empirical findings from the $u k$. Language, Culture and Curriculum. https://doi.org/10.1080/07908318.2018.1563609

Douglas, J. (2009). Children who blog or use Facebook have higher literacy levels. Retrieved 28 August, 2012 from www.debaird.net/blendededunet/2009/12/uk- study-children-who-blogor-use-facebook-have-higher-literacy-levels.html

Drouin, M. A. (2011). College students text messaging, use of textese and literacy skills. Journal of Computer Assisted Learning, 27(1), 67-75. https://doi.org/10.1111/j.1365-2729.2010.00399.x

Drouin, M. \& Davis, C. (2009). R u txting? Is the use of text speak hurting your literacy? Journal of Literacy Research, 41(1), 46-67. https://doi.org/10.1080/10862960802695131

Franklin, R. (2014). Character development. Foreign Policy, (209), 104.

French, J. (2018). Help! My Students Write Like They Text. Rowman \& Littlefield.

Jackowski-Bartol, T. (2001). The impact of word processing on middle school students. Retrieved from http://eric.ed.gov/?id=ED453825.

Kaplan, N. (1995). E-Literacies. Computer-Mediated Communication Magazine, 2(3), 3-35. http://www.ibiblio.org/cmc/mag/1995/mar/kaplan.html

Lenhart, A., Arafeh, S., Smith, A. \& Macgill, A. (2008). Writing, technology and teens. Washington, DC: Pew Internet \& American Life Project. https://eric.ed.gov/?id=ED524313

Merritt, A. (April, 2013). Text-speak: language evolution or just laziness? Retrieved from: https://www.telegraph.co.uk/education/educationopinion/9966117/Text-speak-language-evolution-or-just-la ziness.html

Moyle, K. (2010). Building Innovation: Learning with Technologies. Victoria: Australian Council of Educational Research. Retrieved from: http://citeseerx.ist.psu.edu/viewdoc/download?doi=10.1.1.660.1412\&rep=rep1\&type=pdf

Patea, V. (Ed.). (2012). Short story theories: A twenty-first- century perspective. New York, NY: Rodopi https://doi.org/10.1163/9789401208390

Penny, L. (July, 2014). The great English novel is dead. Long live the unruly, upstart fiction thats flourishing online. New Statesman. Retrieved from: https://www.newstatesman.com/culture/2014/07/great-english-novel-dead-long-live-unruly-upstart-fiction-s -flourishing-online

Rosen, L.D., Chang, J., Erwin, L. L., Carrier, M. \& Cheever, N.A. (2010). Communication Research. 37(420). https://doi.org/10.1177/0093650210362465

Rushkoff, D. (2013). Its not just grammar; its clear thinking. The New York Times. Retrieved from: https://www.nytimes.com/roomfordebate/2012/08/13/is-our-children-learning-enough-grammar-to-get-hire d/its-not-just-grammar-its-clear-thinking

Rudin, M. (2011). From Hemingway to Twitterature: The short and shorter of it. Journal of Electronic Publishing, 14(2), 1-8. https://doi.org/10.3998/3336451.0014.213

Sethi, C. (June, 2017). A Brief History into The Popularity of Micro-Fiction. Retrieved from: https://medium.com/@chaitanyasethi/the-long-and-short-of-micro-fiction-5d66c7fa88d8 
Shariatmadari, D. (2019). Dont Believe a Word by David Shariatmadari review - the truth about language. Retrieved from: https://www.theguardian.com/books/2019/aug/10/dont-believe-a-word-by-david-shariatmadari-review-the-t ruth-about-language

Šesek, L. \& Pušnik, M. (2014). Reading popular literature and digital media: Reading experience, fandoms, and social networks. Anthropological Notebooks, 20(2), 103-126. Retrieved from https://search-ebscohost-com.libaccess.sjlibrary.org/login.aspx?direct=true\&db=a9h\&AN=100267026\&site $=$ ehost-live\&scope $=$ site

Strain-Moritz \& Tessa E. (2016). Perceptions of Technology Use and Its Effects on Student Writing. Culminating Projects in Teacher Development, 8 . https://repository.stcloudstate.edu/ed_etds/8

Sonn, W. (2006). Paradigms lost: The life and deaths of the printed word. Lanham, MD: Scarecrow Press.

\section{Copyrights}

Copyright for this article is retained by the author(s), with first publication rights granted to the journal.

This is an open-access article distributed under the terms and conditions of the Creative Commons Attribution license (http://creativecommons.org/licenses/by/4.0/). 